\title{
Adapting Literature Into Comics and Comparing Hand-Made Comics With Digital-Made Ones
}

\author{
Moula Evangelia \\ Hellenic Open University, Rhodes, Greece \\ Bratitsis Tharrenos \\ University of the Western Macedonia, Florina, Greece \\ Chalkia Sofia \\ Primary Education, Rhodes, Greece
}

\begin{abstract}
In this study we explore the relationship between literature and comics, through the transcription of a literary text into comics, and we examine the contribution of a preceded intervention-familiarization with comics to the students' comics by drawing by hand and by creating them in the Cartoon Story Maker digital environment, aiming at comparing and evaluating the potential of the two media. Literature review reveals that the majority of the educational studies referring to the use of comics in education and the creation of digital comics by students, sets objectives, mainly adjusted to the teaching subject or even to pedagogical issues. On the other hand, they completely bypass the theoretical agenda of comic books and do not ensure a more substantial acquaintance with the comic book itself and the conventions or the meaning making mechanisms of the medium. Thus, we decided to conduct this study in order to fill the gap in the existing literature. According to the findings, the preceding teaching intervention had been constructive but the digital tool's technical restrictions prohibited the full making use of the acquired knowledge concerning the language of comics. The hand-made comics were more imaginative and detailed in certain statistically significant factors. Regarding the relationship between the literary text and comics, the students adapted the literary language to the media specifications, remaining in both cases, mostly faithful to the main structure of the text.
\end{abstract}

Keywords: literature transcription, hand-made comics, digital comic reator tools

\section{Introduction}

In comics, word and image co-operate in producing storytelling within a large scale of possible interactions (Carier, 2000, p. 68). This is why comics' attribution can be multidimensional, enunciable, descriptive and also interpretable (Groensteen, 2007, p. 126). They occupy an intermediate zone, cross-fertilizing elements and conventions from both kinds of literacy, verbal and visual. Groensteen (2007) considers comics as a language by itself, as a "set of productive mechanisms of meaning".

Moula Evangelia, Dr. C.E.P. at Hellenic Open University, Rhodes, Greece.

Bratitsis Tharrenos, Dr.,Associate Professor, University of Western Macedonia, Florina, Greece.

Chalkia Sofia, Primary Education, Rhodes, Greece. 
Nevertheless, comics in educational scenarios are usually handled in a reductionist way, as informational carriers, or as a creative activity by definition, ignoring the wealth of the image (Miodrag, 2013, p. 18), which is erroneously treated as a supplementary, or ornamental decoration.

Comics thus are mistakenly used to transfer a pre-planned dialogue between fictional or real persons into panels, without even any effort to adapt the dialogue to the medium's specifications and conventions (Moula, 2016) and without taking into account the content condensation required by the medium or its particular meaning making devices. (see: Gerakini, 2015; Amanatides \& Kolokytha, 2015; Markou \& Tourambelis, 2015; Vlachokyriakou, Kalopisi, \& Tzortzakis, 2011).

The educational use of digital environments for comics' creation mainly underpins:

- the promotion of students' narrative and linguistic skills (Amarantidou \& Pigaridou, 2016),

- the acquisition of digital skills, like utilization of hyperlinks, sound, images and generally multimedia add -ons (Vassilikopoulou, 2008),

- the artistic aspect of illustration, but without clearly defining its evaluation criteria,

- the engagement and the motivation of the reluctant students (Trimi-Kyrou, 2011),

- the improvement of students' collaboration, as well as

- the fostering of students' creativity.

It is noted that the majority of the proposed teaching interventions completely bypass the theoretical agenda of comic books and do not ensure a more substantial acquaintance with the comic book itself and the conventions of the medium, while capitalizing on the use of multimedia resources (Nezi et al. 2009).

Furthermore, regarding the comparison of analogue and digital comics, opinions differ. Sometimes the surveys evaluate and compare digital to analogue comics, proving the primacy of the first (Katsavou, Oikonomidis, \& Kavvoura, 2013) and other times (Moutafidou, Melliou, \& Bratitsis, 2016) they conclude that the use of digital comics, regardless of the dynamics available, does not ensure the creation of quality stories. Essential prerequisite for successful exploitation of the digital tools is the contribution of teachers in designing appropriate activities and in supporting students handling the digital comic creation tools.

Hence, we decided to conduct this study in order to fill the gap in the existing literature and to further explore and clarify the potential of the two ways of creating comics, setting more formal criteria, relevant to the medium itself and not only with the pedagogical aspects of similar didactic interventions.

\section{Theoretical Background}

The theoretical background of our study was founded on Multiliteracies, as proposed by The New London Group (1996) and the respective multimodality theory in the digital environments (Miller \& McVee, 2012). Multiliteracies' pedagogy encourages a wide range of perspectives and tools being used to help students better prepare for a rapidly changing world.

Meaning-making in modern technological and socio-cultural conditions has greatly reformed the communication of individuals, as long as it is mainly conducted in new electronic environments, creating a new textual reality based on multimodal-multimedia texts, which are mainly produced by new digital media (Kalantzis \& Cope, 2001; Unsworth, 2008). 
This new communicative order also affects teaching, as students of the net generation need not only communicate in written form or by using spoken language, but by any available resources. The meaning is molded with methods that are becoming increasingly multimodal. The pedagogy of multiliteracies proposes a teaching based on texts related to students' everydaylife, as "literacy can not be separated from the world in which they live" (Bruce, 2007, p. 8).

Therefore, this theory has been developed in response to the vacuum of traditional literacy practices, ignoring modern multimodal turn and the new skills required in order to communicate effectively in the new digital environments.

Therefore, we chose to use comics. The act of reading comics is a substantially complicated activity that dynamically integrates simultaneous understanding of language and image (Edwards-Groves, 2011). Comics are predominantly hybrid products that obscure the categorical boundaries between the world said and the world seen (Moula, 2015), being a mixture of heterogeneous elements, both iconic and symbolic (Magnussen-Christiansen, 2000, p. 47).

\section{A Concise Review of the Complex Relation Between Education and Comics}

Comics, both as an expressive medium and as a tool for teaching always raised strong objections among teachers and the academic community. There have been and still are strong controversies about their educational value and appropriateness. However, in recent years, it seems that in the academic world, proponents of the active use of comics (in their various forms, e.g. comic-strips, graphic novels, motion comics, etc.) in education outmatch those that are either reserved or adversely predisposed towards them (Moula \& Malafantis, 2015, p. 45).

Originally, comics were accused of weakening both the young people's imagination and linguistic skills, since they were perceived as an easy digestible "food" that overrides comics' reception began to reverse (Hartfield, 2009). The novelty of the term graphic novels has been catalytic for the more positive engagement the reading of literature, which is far more educational (Moula \& Koseyan, 2010, p. 31).

Since the 1980s, when a series of pioneering comic books had been released, like Maus and Watchmen, comics' reception began to reverse (Hartfield, 2009). The novelty of the term graphic novels has been catalytic for the more positive engagement with comics by the educational and academic status quo (Moula \& Malafantis, 2015 , p. 43). "Many of today's teachers use comics to encourage the very qualities that teachers at the 40s accused comics of ruining: language learning and enhancement of imagination" (Yang, 2003). Also, within the context of the expanding and growing recognition of the importance of critical, visual and other kinds of literacy (Jewitt, 2008), which were in the past considered secondary, more attention has been paid to comics, especially in their recent popular version, of graphic novels (Carter, 2007, p. 1). In addition, the demand for more democracy and the use of the arts in education are additional factors which have contributed tothe flourishing of the academic debate around the issue and the positive turn towards the use of comics in education.

\section{Brief Description of Research Stages}

Having noticed that in the majority of the teaching interventions, there is an absence of a critical approach to the comics' language and conventions, which could guarantee a more conscious and meaningful exploitation of 
the medium's potential, it was decided to start with a teaching intervention-presentation, to familiarize the students with comics' codes and variety.

Our goal was the better and broader understanding of comics' functions and conventions, the demonstration of comics' differences from other expressive mediums (illustrated book, animation) and the negotiation of the dominant stereotypical perceptions about comics.

A previous research, on which our introductory teaching intervention was based, was that of Pantaleo (2015). In particular, the researcher proves the importance and the positive contribution of students' familiarization with the particular features of the medium and its meaning making mechanisms, in understanding, interpreting, analyzing and creating comics, after having compared their products before and after her intervention.

The multiliteracies' theory was applied, as following:

At the first stage, during situated practice, students brought their own, invariably diverse knowledge, experiences and interests to the learning context (we made a discussion about comics and handed out a questionnaire).

Afterwards we moved towards critical framing, by applying our teaching intervention. We presented to the students as many aspects as possible concerning comics (material, sensorial, semiotic, cultural), in order to help them reconceptualize comics and subvert the usual reductionist views.

Then, we went through the phase of overt instruction, when we supported students to analyze the literary text and familiarize themselves with the digital comic creation tool.

And finally we ended up with transformed practice, when the students were asked to apply their knowledge into the required settings, which meant to transcribe the literary text into comics created by hand and by the digital tool.

\section{Implementation}

This research scenario took place at the IT Laboratory of the primary school at Koskinou in Rodos, Dodecanese, from January to March 2017. To the 80 students we distributed: (a) a questionnaire in order to pre-evaluate their knowledge on comics before the intervention; (b) worksheets to draw their comics by hand (one worksheet per group of students); and (c) a questionnaire for the students to evaluate the whole procedure, as well as the tool's usability upon the activity's completion.

Before we started, we had already installed The Cartoon Story Maker software on the desktops of the laboratory and we had also saved a folder on each desktop with various images, for optional use by the students, since they were also allowed to search for images on the web. Among the various software and web applications available, we had to apply some selection criteria, necessary for the implementation of our scenario, given the age of the students, their limited knowledge on computers, the logistical infrastructure of the school, the teaching subject and its needs. For all the above mentioned factors, the tool we chose had to be installable on a computer, to have a simple and functional user interface, to support Greek fonts, to allow the import of images, multimedia and hyperlinks, the adjustment and the editing of the imported objects and to allow the products to be exported in accessible formats.

After our presentation, we distributed various comic books to the students and they were asked to identify features and codes that had been presented and discussed. To a large extent, the students were able to respond, 
proving that they had understood and assimilated most of the information presented.

In the next phase, the students read an excerpt of the literary text by Menelaos Lountemis, "A child counts the stars" from their textbook, which we had selected according to the following criteria: it has a clear tripartite structure (equal to the available panels), it combines various narrative modes: dialogue, narrative, action and internal monologue and it allows, in the absence of exhaustive details, the students' imagination to unfold.

In addition, it was considered pedagogically appropriate, since it was about the love of a small child for books. The excerpt of Menelaus Lountemis, "One Child Counts the Stars" (included in the Anthology of the 5th and 6th level), was read aloud and commented upon by the students. They then divided it into three basic scenes: the first when the child asks the old man for a book, the second when the old man brings him the book and the last, when the child reads the book with enthusiasm. Students were prompted to handle the passage as they wished, without being restricted by the above formal division of the narrative.

They were divided into couples and worked collaboratively, in order to create a non-competitive environment, to discuss and take decisions in common, to exchange ideas and be mutually assisted when needed. However, this grouping was also done with some criteria that served the best course of the venture, taking into account the students' convenience to handle the software (Kossivaki, 2006) or their ability to draw.

\section{Assessment Rubric-Setting Criteria}

Finally, we compared the results between the students' works by hand and by the digital tool, looking for similarities and differences. For the assessment rubric of the students' projects, we chose criteria that could be evaluated objectively and quantitatively, so as to get results as measurable as possible. For the statistical processing of the outcomes we used the SPSS v.17 software and we applied the non-parametric criterion Mann-Whitney.

The rubric criteria, evaluated in the likert scale, were as follows:

Are words-phrases copied from the literary text?

Is the text attributed freely but still remains faithful to its meaning?

Is the text attributed freely but its original meaning is modified or altered?

Are there any figurative or imaginary elements that do not originate from the text?

Are there panels without text?

Are there only text panels (without image)?

Does the rendering of the space match the description of the text?

Do words and image complement each other?

Do words and image contradict?

Is the narrative satisfactorily given?

Are there any textual details (identifiers, time info) drawn?

Are people's thoughts attributed?

Is zoom device used?

Are the horizontal (lateral positioning) or vertical axis (from high or low) exploited?

Are any graphic comics' conventions used (emanate)?

Are there motion lines? 
Are visualized sounds used?

Having investigated the students' relationship with comics through the introductory questionnaire at the early stage of the study, we noticed the following: While the majority of children claimed that they read comic books $(66 \%)$ and that they prefer them from the illustrated books, to the question how often they read comics, the rate dropped down radically ( $36 \%$ often, $74 \%$ rarely).

Furthermore, in their unawareness to distinguish the difference between comics and animation and also to mention comic book titles, it has been realised that students don't have a clear conception about comics, they confuse the media that contain cartoon-like characters and treat them as one.

In relation to our above mentioned conclusions, we can safely claim that the teaching intervention which had preceded, benefited the students and provided them with information they did not possess earlier, clarifying ambiguities and widening their cognitive horizon about comics. This was also verified by their own final evaluation of the intervention through the last short questionnaire, which was distributed to them, after the completion of the activity. $82.5 \%$ of the students responded that they had learnt things they did not know about comics, and $95 \%$ of them, agreed that this knowledge was expressed in their works efficiently.

\section{Conclusions From the Transcription of the Literary Text Into Comics}

When transcribing the literary text (settings, characters, plot) into comics (regardless of the means the students used), they adapted the literary language to the media specifications and condensed the analytical literary discourse into a form, appropriate to the spatial particularities and the reading rate of the comics (they had during the intervention been informed about these features). They did not use any exact phrases from the text, but they reworked it and presented it in their own words. The relationship between literary narrative and comics was not significantly differentiated by the way comics were created (by hand or by the tool).

Despite the fact that the text was freely rendered, it remained faithful to its content and main structure, a fact that proved that the children had comprehended its thematic centers during the processing of the text.

The word and image combination was that of enhancement (Nikolajeva \& Scott, 2006), meaning pictures expanded upon the words or vice-versa and there was no counterpoint or contradiction noticed, as expected. In McCloud's terminology (1993) we would claim that words and pictures had an additive or an intersective quality, meaning words amplified or elaborated on an image and vice versa, or they worked in unison to produce meaning.

The attribution of the space-background was highly consistent with the description of the text (rural scenery with details referring to agricultural occupations). Sometimes, however (23\%), children moved action into other environments, transferring the characters to urban surroundings, which obviously echoed their own experiences. The story was in general adequately attributed and without meaningful gaps or omissions at $76.2 \%$. Rarely, due to lack of time, the story was not completed.

\section{Conclusions From the Comparison Between Hand-Made and Digital Comics}

Having applied the formal criteria on students' works, we found out that:

The text was rendered more freely by hand and in a more detailed way (indications of time, secondary information and objects). The percentage was $46.75 \%$ by hand vs. $34.26 \%$ by the digital tool (e.g. the job of the 
old man, who was a corn seller, the rural environment of the village, the winter time), while the already stored images in the pc folders, or those derived from internet did not allow the students to highlight the details. In the hand-made comics also figurative elements, motion lines and visualized sounds were also detected, which were not derived from the text.

The rendering of invented visual elements, not derived from the text, is intense in the works of the children by hand (54\%) and almost non-existent in the digital works (26\%). The students enriched the descriptions with imaginary details, such as a car that carried the book or a carpentry where the child worked etc.

The reason that in the comics created by hand the original meaning had been interpreted more loosely, is likely to be due to the fact that the children's imagination was released without the technical restrictions of the tool or the results of the search engine.

Regarding the visualized sounds, which are a particular feature of the comic language, these appeared more often in the handmade works (45\%) and less in digitally made ones (30\%), because the tool did not provide a stock of ready-made visualized sounds and the students had to design them manually, modifying the available speech balloons.

At the same time, the motion lines, which are one of the most significant elements of the comic language, were comprehended by the students through the preceded teaching intervention, since they were used to a significant extent in the works by hand (52\%), but they were not used at all in the works by the tool, since this feature was not available. In fact, no digital comic creation tool offers this feature in its free version. Instead, it can be found on a variety of other tools, in their upgraded version (Manga studio, Sketchbook pro, Comic creator, Poser pro, Corel painter, Motion artist).

In the works created by the digital tool, the statistically important factors detected, compared to those by hand, were the attribution of the persons' inner thoughts in speech bubbles, the use of zoom technique and the exploitation of the horizontal (lateral positioning) axis.

Students attributed the inner thoughts and feelings of the persons, mostly in the digitally created comics ( $52.18 \%$ versus $28.83 \%$ by hand), because the existent choice of the particular kind of cloud in the tool's library, recalled in their memory what they had been taught and facilitated its use.

As far as it concerns the zoom technique which sets the distance between the depicted on an image and the viewer (Kress \& Van Leeuwen, 1996) and controls the quality of communication and the degree of immediacy with the viewer, the students understood the mechanism, but they managed to express it mainly through the digital tool, which provided them with the specific possibility to move-zoom in and out-the objects. On the contrary, their elementary design skills, because of their age and the lack of specialized artistic education, did not allow them to take advantage of the technique while drawing by hand ( $47.56 \%$ vs. $23 \%$ ).

The lateral axes were only exploited in the works by the tool, while in those by hand the representations were more centrally positioned and all figures were frontal.

To sum up, we would argue that whenever a statistically significant difference was observed, it was related to the particularities of the digital tool, either by facilitating students (for example, zooming, clouds of thought) or by causing them difficulties or imposing them restrictions (ready images, absence of visualized sounds or motion lines). Therefore, the research results prove the importance of the digital environments in the creation and quality of students' comics, as long as the features they dispose, are the most important factors in the outcome of their 
artefacts, more than other individual skills.

The relationship between literary narrative and comics was not significantly influenced by the way comics were created (by hand or by the tool).

It was confirmed that the teaching intervention had been constructive, but also that the tool's technical restrictions prohibited the full making use of the acquired knowledge concerning comics. As far as it concerns the transcription of the literary text into comics, results proved that the procedure released children's imagination in minor factors, though the structure of the text remained in general terms faithful to the original, without any major deviations from the plot.

\section{Research Restrictions and Further Suggestions}

The small number of the sample ( 80 students) is an obvious limitation of the research, which should probably be applied on a bigger sample of students to reach more reliable and generalizable conclusions.

Another constraint was the focus on the particular age group. It is likely that the findings would be differentiated if the research was applied to students of different levels, with either less developed or even more mature, perceptual and design skills. It would be interesting to compare different age groups.

A third limitation is related to the choice of this specific tool, thanks to its free access and its quality to run offline. The tool has significant shortcomings in comics' language and creation mechanisms and it did not offer the technical choices to allow students to make best use of the knowledge that they had acquired through the teaching intervention. The research could also be extended to more comics creation digital tools to identify the role of their features and their available resources in creating comics.

Equally, it would be of interest to assess the effectiveness of the teaching intervention by comparing the works of two different groups (one experimental and one control group), with the first of them being submitted to the intervention and the other not.

\section{References}

Bruce, B. C. (2007). Diversity and critical social engagement: How changing technologies enable new modes of literacy in changing circumstances. In D. E. Alvermann (Ed.), Adolescents and literacies in a digital world (pp. 1-18). New York, NY: Peter Lang. Carier, D. (2000). The aesthetics of comics. University Park PA: The Pennsylvania State University Press.

Carter, J. B. (2007). Building literacy connections with graphic novels. Page by page, panel by panel. Urbana: IL, National Council of Teachers of English.

Edwards-Groves, C. (2011). The multimodal writing process: Changing practices in contemporary classrooms. Language and Education, 25(1), 49-64.

Groensteen, T. (2007). The system of comics. Jackson: University Press of Mississippi.

Hartfield, C. (2009). Defining comics in the classroom; Or, the pros and cons of unfixability. In E. S. Tabachnick (Ed.), Teaching the graphic novel (pp.19-27). New York: The Modern Language Association of America.

Jewitt, C. (2008). Multimodality and literacy in school classrooms. Review of Research in Education, 32(1), 241-267.

Kalantzis, M., \& Cope, B. (2001). Multiliteracies. In A. Christides (Ed.), Encyclopedic guide to the language (pp. 214-216). Thessaloniki: Center for Greek Language.

Kress, G., \& Van Leeuwen, T. (1996). Reading images. The grammar of visual design. London: Routledge.

Magnussen, A., \& Christiansen, H.-Ch. (2000). Comics \& culture: Analytical and theoretical approaches to comics. Copenhagen: Museum Tusculanum Press, University of Copenhagen.

McCloud, S. (1993). Understanding comics. The invisible art. New York, NY: Kitchen Sink Press for Harper Collins.

Miller, S., \& Mcvee, M. (2012). Multimodal composing in classrooms: learning and teaching for the digital world. New York, NY: Routledge, Taylor \& Francis Group. 
Miodrag, H. (2013). Comics and language. Reimagining critical discourse on the form. Jackson: University Press of Mississippi. Nikolajeva, M., \& Scott, C. (2006). How picturebooks work. New York: Routledge.

Pantaleo, S. (2015). Exploring the intentionality of design in the graphic narrative of one middle-years student. Journal of Comics and Grpahic Novels, 6(4), 398-418.

The New London Group. (1996). A pedagogy of multiliteracies: Designing social futures. Harvard Educational Review, 66(1), 60-93.

Unsworth, L. (2008). Multiliteracies, E-Literature and English teaching. Language and Education, 22(1), 62-75.

Yang, G. (2003). Comics in education. Online version of the final project proposal for masters of education degree at California State University at Hayward, Retrieved 1 December, 2016, from: http://www.humblecomics.com/comicsedu/index.html

In Greek

Amanatidis, N., \& Kolokytha, P.-A. (2015). A Teachers 4 Europe Program at Primary School on School Intimidation. In Proceedings of the Conference Education in the Times of ICT (pp. 936-946). Athens, 7 and 8 November 2015.

Amarantidou, K., \& Pougaridou, P. (2016). Direct and indirect speech. An alternative proposal for teaching in elementary school through comics. In Proceedings of the Conference New Pedagogue (pp. 1909-1920). Athens, 3 and 4 May 2016.

Gerakini, A. (2015). ICT and creative writing for the approach of the 2 nd Greek colonization. In Proceedings of the Conference Education in the Times of ICT (pp. 982-999). Athens, 7 and 8 November 2015.

Katsavou, N., Oeconomidis, D., \& Kavvoura, H. (2013). A cooperative Web2 pedagogical activity of the implementation of digital comics in environmental education-Transition from analogue to digital comic of the story: ECOMAN in new adventures. In Proceedings of the 10th Conference on Education in the Era of ICT (pp. 718-725). Athens. 19 and 20 October 2013.

Kossyvaki, F. (2006). Alternative didactics: Proposals for transition from the subject to the teaching of the active subject. Athens: Gutenberg..

Markou, P., \& Touroumbelis, M. (2015). Exploitation and implementation of ICT in the teaching of Modern and Contemporary History-An interdisciplinary didactical approach. In Proceedings of the Conference Education in the Times of ICT (pp. 1443-1453). Athens, 7 and 8 November 2015.

Moula, E. (2016). Printed and digital comics, digital comics creation environments and educational practices: Characteristics, transformations, trends and identities. In Proceedings of the Conference Education in the Times of ICT and Innovation. Athens. November 2016.

Moula, E., \& Koseyan, Ch. (2010). The use of comics in education teaching suggestions-Pedagogical extensions. Athens: Kritiki.

Moula, E., \& MalafantiS, K. (2015). Word clouds: Comics and New Literacies. Athens: Comicon.

Moutafidou, A., Melliou, K., \& Bratitsis, T. (2016). Digital comic as means of creating stories in Kindergarten. 10th Pan-Hellenic and International Conference "ICT in Education", University of Ioannina, Ioannina, Greece, 22-25 September 2016.

Nezi, M., Vassilakopoulou, M., Boloudakis, M., Altinis, I., \& Retalis, S. (2009). Pilot use of digital comics teachers in the teaching of the Modern Greek language course in the first grade of high school. At the 5th Panhellenic Conference of EYEP-DTPE for School 2.0, 17-18 October 2009 (pp. 314-325) Piraeus.

Trimi-Kuyrou, A. (2011). In the structure of a narrative text with vehicle a digital comic. In Proceedings of the 8th Panhellenic Conference on Digital School (pp. 627-635). Piraeus, 22 and 23 October 2011.

Vassilikopoulou, M., Boloudakis, M, Arapogloy I., Altanis I., Georgiakakis, H., \& Retalis, S. (2008). Results of a pilot workshop for the use of educational digital comics in primary and secondary education students. 5th Pan-Hellenic EEEP-DTPE "ICT \& Education" Conference. Pireaus. 4 and 5 October 2008. Retrieved 10 May 2016 from: http://www.comicstripcreator.org/files/papers/UsingDigitalComics.pdf

Vlachokyriakou, F., Kalopisi E., \& Tzortzakis I. (2011). Exploitation of digital comics in secondary education. In Proceedings of the 8th Pan-Hellenic, EEEP-DTPE Congress on Digital Education (pp. 18-26). Pireaus, 22 and 23 October 2011. 